\title{
Discussion and Practice on Professional Feature Teaching of Engineering Drawing Course
}

\author{
Yu LIU ${ }^{1, a,{ }^{*}}$, Ning LIU ${ }^{2, b}$ \\ ${ }^{1}$ School of Mechanical and Power Engineering, Henan Polytechnic University, Jiaozuo, 454000, \\ China \\ ${ }^{2}$ School of Mechanical and Power Engineering, Henan Polytechnic University, Jiaozuo 454000, \\ China

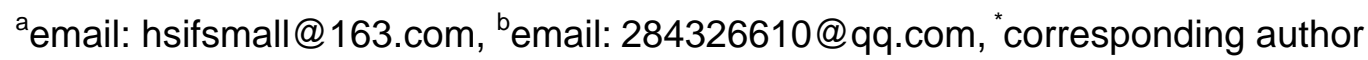

\begin{abstract}
Keywords: Soccer Robot, Mechanical Analysis, Optimal Design Engineering Drawing, Professional Feature, Practical Application Ability, Curriculum Design
\end{abstract}

\begin{abstract}
The engineering drawing course is an impprtant course with strong applicability. The present problem for the course is that the teaching process has few connections with professions and students are not interested in the course. It is the main cause of the reduction of teaching quality. In order to improve the relevance between engineering drawing course and professions as well as enhance the practical application ability of students, four suggestions have been put forward in this paper. The first one is determining the teaching outline with different majors. Professional drawing knowledge and practice training should be included into the teaching outline. The second one is indicating the application value of engineering drawing in professional fields. Teachers should enhance introduction of professional drawing knowledge and encourage students to discover the applications of engineering drawing course in their professional fields. Emphasizing the improvement of practice ability is introduced as the third one. Students are required to survey and draw practical products for consolidating the theoretical knowledge. Formulating curriculum design contents combining with different majors is proposed as the last one. The problem of curriculum design should be connected with professions and have a clear aim and moderate content. The enough time and fixed place should be applied for students to complete their design absorbedly.
\end{abstract}

\section{Introduction}

Engineering drawing course, a compulsory foundational course for engineering majors, is usually set up in freshman year to emphasize the significance, fundamentality and practicality. In recent years, most of students feel that it is difficult and effectless in the study of this course, because of compressing periods and increasing class capacity[1][2]. Meanwhile, as a liberal education course, the contents of engineering drawing course have few relations with professions and have no embodiment of practical values, which is another important factor that confines students to study the course earnestly. Although several textbooks relating to professions have been applied partially, e.g. the electrical engineering drawing[3], the chemical engineering drawing[4] and the firefighting engineering drawing[5], there are still many universities in which the teachers of engineering drawing course mainly research on graphics and the textbooks are compiled for liberal education. How to motivate the enthusiasm of students has caught greater attentions of teachers in order to enhance the quality of teaching. Engineering drawing course should not be divorced from practical applications, so the teaching and learning of this course must be linked to professional feature. With lessons learned during this course, four suggestions are introduced on professional feature teaching of engineering drawing course in this paper aimed at acquiring better teaching effects in different majors.

\section{Determining the Teaching Outline for Different Majors}

The teaching outline of engineering drawing course is generally divided into two or three levels as a liberal education course. For different majors, the college can select a suitable level according to the 
professional requirements. Nevertheless, the teaching outline is designed for many majors where teaching objectives of the course are similar to each other, and not for mono major with professional feature. Taking Henan Polytechnic University for example, there are two levels for engineering drawing course, named level A and level B. Level A is applied for safety engineering, firefighting engineering and material engineering while level B is deployed for electrical engineering, chemical engineering, surveying engineering and any other majors. The same teaching outline leads to no professional feature during teaching process and fewer learning interests of students. As a result, students learn the course only for examination and credit, which is the significant cause of the reduction of teaching quality.

In order to solve the foregoing problem, it is suggested that the teaching outline should be connected with majors, which means that all of principle knowledge points are related to graphics applications in professional field except for the basic projection theory. However, revising the teaching outline is a painstaking and complicated task leading to enormous workload for teachers. Concerning that the basic projection theory, drawing standards and three views of combination solids are foundational contents for each major, these contents will be remain unchanged as a principle part of the teaching outline. Professional drawing contents will be added into the teaching outline. The teachers of engineering drawing course and professional course confirm the professional drawing contents together through communication and discussion. This part of the teaching outline, embodying professional features of different majors and improving application ability of students efficiently, must contain the national and professional standards, the ability of drawing and reading professional drawings as well as the ability of employing knowledge comprehensively to express own design idea.

\section{Indicating the Application Value of Engineering Drawing in Professional Fields}

Most students learning engineering drawing course are in freshman year. They understand little about their majors and are unable to realize the application of engineering drawing in professional fields. Numerous students consider that engineering drawing course has no application value, which affect their study enthusiasm and impetus directly. However, when communicating with senior students, they always sigh with emotion: contents in engineering drawing course have an extensive use during our graduation projects, and we did not study hard at that time. As a result, now we need to study the course on our own. It is showed that students can realize the significance of the course only after the practical application. Therefore, teachers are required to transmit the application value in professional fields to students, and make students take the course seriously. If learning attitude can be changed from passive to active, learning effect will be improved enormously.

Enhancing Introduction of Professional Drawing Knowledge. Teachers of engineering drawing course have less chance to contact with professional applications, which extremely confines the conduct of professional feature teaching of the course. For this reason, teachers of engineering drawing course are encouraged to participate into professional research groups, or at least understand basic knowledge of professions. It is an effective method of strengthening connection between engineering drawing course and professional applications. Teachers possessing professional knowledge can provide a better guidance for students to realize the application values of engineering drawing course in their majors.

In the introduction of engineering drawing course, teachers should demonstrate the significance of the course in professional fields combining with engineering projects. For chemical engineering, there are chemical containers drawing, piping diagrams and process flow diagrams as well as for electrical engineering, there are electrical diagrams and circuit diagrams. Students may have a keen interest in studying engineering drawing course as long as they know that the course has a tremendous application in their professional fields.

During subsequent teaching process, professional applications should be infused into the course system persistently. For electrical engineering, household electric appliances are able to be employed for classroom teaching. Aimed at mastering the drawing skills and basic projection theory, students are required to draw the three views of clever pedestal of water fountain as shown in Fig.1. 
The related circuit diagram of water fountain is adopted to explain the implication and drawing of basic circuit symbols, which is depicted in Fig.2. With the practice mentioned above, students can learn both drawing basic knowledge and electrical drawing knowledge, and convince of practical application value of engineering drawing course.

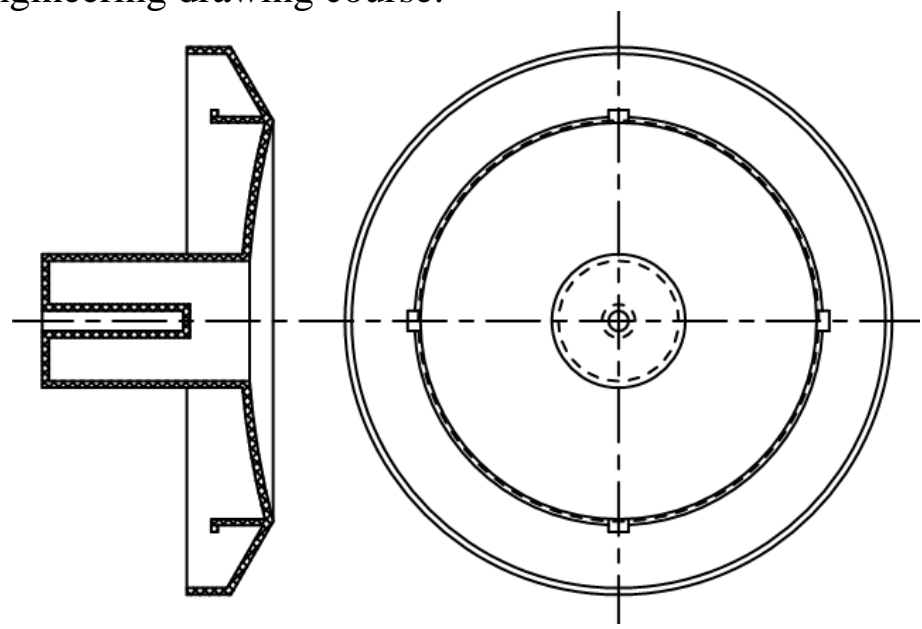

Fig. 1 Three views of clever pedestal of water fountain

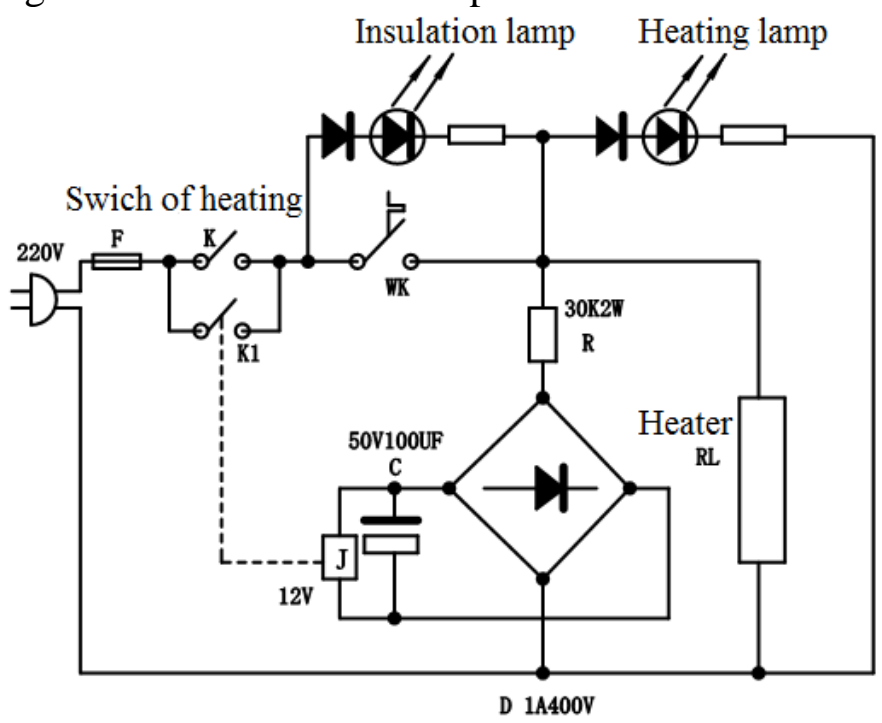

Fig. 2 Circuit diagram of water fountain

Encouraging Students to Find out the Application of Graphics in Their Professional Fields. Knowledge comes from the practice and must be applied to the practice as well. It is insufficient that students learning engineering drawing course only dependent on explanations by teachers. Intending to comprehend the application value of the course thoroughly, students need to discover the application of graphics in their professional fields proactively. Therefore, the opportunities of practice should be utilized reasonably. Teachers can organize students to visit the curriculum design classrooms, where students may validate the importance of graphics by exchanging experience with students in senior class. Moreover, teachers are also allowed to assign a certain range for students to explore products requiring the knowledge of graphics to guide design and manufacture. By means of own observation, students demonstrating application values of engineering drawing course, will throw themselves into study and improve the ability of drawing and reading professional drawings energetically.

\section{Emphasizing the Improvement of Practice Ability}

Engineering drawing course with strong practicality is capable of increasing the drawing knowledge, drawing skills and spatial thinking ability of students. Whereas, teachers are generally focused on the basic projection theory and national standards, which leads that the course is divorced from 
practical application and students are ignorant of what can the course do in production. For this reason, it is suggested that the practice training should be added to the teaching process. Taking three views as an example, exercises in workbooks are all limited to models of combination solids [6]. It may be implied that only models need to be drawn into three views. As a result, students have no idea how to draw a reality product. If students have an opportunity to draw three views of the components of equipment on the spot, their practice ability must be improved tremendously. Furthermore, teachers can correct the problem that students encounter without delay as well as students can consolidate the theoretical knowledge through their own practice.

Except for the practice of the basic projection theory, teachers are also supposed to design some practice trainings in allusion to professions of students. For instance, conical head is a common component of pressure vessels for the chemical industry. Teachers who teach students in chemical engineering may explain the function, processing method, application range and universal drawing method of conical head, and require students to give the engineering drawing of conical head. By means of drawing and reading the engineering drawings of equipments relating to professional fields, students are able to realize the significance and practicability of engineering drawing course.

\section{Formulating Curriculum Design Contents Combining with Different Majors}

Engineering drawing course is usually accompanied by curriculum design, which is an important way to offset the insufficient of classroom teaching and increase practical operation ability. However, confined by period, teachers have no enough time to give a deep and detailed explanation in the classroom, which causes that students do not understand the method and technique adequately. During curriculum design process, tutorship of teachers is trapped on account of the review for a test and constraint of time. Consequently, many students copy each other and accomplish their design perfunctorily. The situation above leads that students are unable to improve their ability in the curriculum design, which have a great influence on the drawing of practice training of following courses and the quality of graduation projects.

Selecting a Problem Relating to Professions. To obtain a better effect, curriculum design needs a univocal problem with abundant contents. Communicating with teachers of professional courses, teachers of engineering drawing course should formulate the contents relating to professions according to the situation of students. Considering that freshmen have less professional knowledge, the problem of curriculum design with clear aim and moderate content is supposed to connect with professions and is not divorced from actual livelihood. Teachers should lead students to consult technical literature, learn a little professional knowledge automatically and complete curriculum design on the basis of comprehension.

The problem for students in electrical engineering may be chosen to design a geometric modeling coloured lantern. Electrical part of coloured lantern is a mature technology, so students can draw the circuit diagram by reference to literature or designing a new control circuit themselves. Regarding traditional drawing, the requirement is to design a complex geometric modeling and draw the three views. Fig. 3 shows one of the three views of geometric modeling coloured lanterns designed by students. Teachers can encourage students to produce their design so that the operational ability of students is also exercised and improved.

Doing Everything Possible to Ensure the Quality of Curriculum Design. After selecting the problem reasonably, the powerful guarantee should be given in order to conduct the curriculum design successfully. On the one hand, there should be enough time and fixed place. One week is required at least for students to accomplish their curriculum design absorbedly, and the special classroom is also needed for students to design and draw as well as for teachers to provide guidance. On the other hand, teachers should attach more importance to the content linking to practice training, such as component modeling and mapping. For example, teachers can afford several feasible modeling designs to extend the ideas of students and instruct students to drawing the three views, which lays a foundation for curriculum design. In addition, in view of the insufficient professional knowledge, the approach of data retrieval is supplied by teachers to make students retrieve the content in the library or on the Internet. 


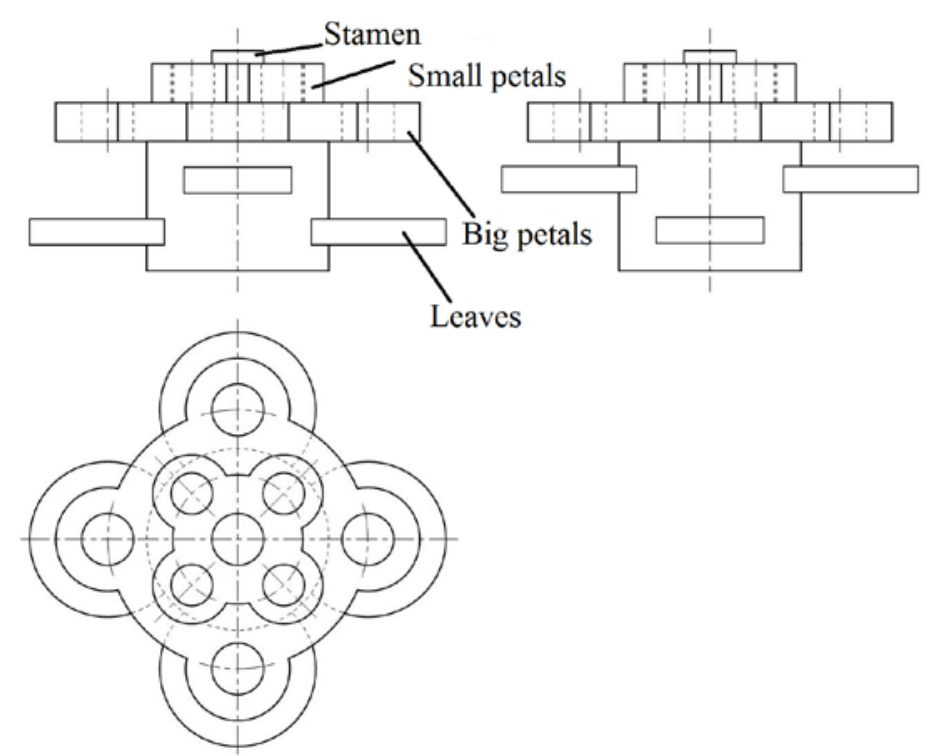

Fig.3 Design of geometric modeling coloured lantern

\section{Summary}

Engineering drawing course is a foundational course of engineering majors, which has important applications in livelihood and production. How to couple the course closely with professions is the problem concerned by many teachers. Four suggestions are proposed from aspects of the teaching outline, course teaching and curriculum design. It is expected that the suggestions are helpful for professional feature teaching of engineering drawing course and play a role in improving the teaching quality.

\section{References}

[1] D.C. Yang, Y.K. Wang and X.Z. Li, Discussion about teaching method of mechanical drawing course[J], Journal of Engineering Graphics, 2 (2007) 183-187.

[2] M.L. Yu, Reflection and exploration to the teaching reform of engineering drawing[J], Journal of Engineering Graphics, 5 (2009) 157-162.

[3] Q.Zhang, Exploration on integration teaching of electrical drawing and $\mathrm{CAD}[\mathrm{J}]$, China Power Education, 8 (2008) 119-120.

[4] D.L. Zhu, W.Y. Li, Exploration on integration of contents and reform of exam in chemical drawing course[J], Journal of Jilin Institute of Chemical Technology, 32 (2015) 63-66.

[5] F. Zhang, Z.H. Chen and X.Q. Zhang, Innovation of teaching methods for fire drawing course[J], Journal of Langfang Teachers College (Natural Science Edition), 14 (2014) 116-117,120.

[6] Y.Q. Bai, Y.L. Mo, Workbook of modern mechanical engineering drawing[M], China Machine Press, Beijing, 2013. 